\title{
Educational buildings as part of sustainable urban planning
}

\author{
L. Chlasta \\ University of Technology and Life Sciences in Bydgoszcz, Poland
}

\begin{abstract}
Buildings having educational features (besides trade, culture, sport and recreation) are the most desirable neighbourhood in the area of housing. If they are not at a reasonable distance, local communities demand to build the appropriate buildings. If there is an educational building and it is too small, locals try to upgrade the environment. The authorities are trying to solve the problem of appropriate location of educational infrastructure because of its great importance and public interest. They do this despite the high cost, not only related to the construction or expansion of such facilities, but also in spite of the high maintenance costs. The aging as well as other fluctuations of the population, like migration to and from the city to suburbs or rural areas and the development of new housing can generate problematic situations. Certain areas of the city are underpopulated, while others are overpopulated with regard to educational infrastructure, resulting in, for example, schools having too few or too many students. This phenomenon is particularly evident in larger cities and in adjacent areas where significant expansion of suburbs occurs. New development areas are relatively far from the locations where schools are currently oversized. This serious problem goes far beyond the financial consequences and affects the quality of education and safety, at the same time increasing traffic and hence also the environment.

This paper will attempt to diagnose and systematize selected strategies aimed at appropriate designing and location of educational facilities. It will propose the way of diagnosing and balancing negative effects, and it will define how to transfer these analytic findings into a design process to acquire sustainable solutions using a Polish-centred perspective.
\end{abstract}

Keywords: density of schools, distance from the school, distribution of schools. 


\section{Introduction}

Distribution of schools is a major problem in the process of both the planning and management of cities or communities. The greatest difficulty lies in the optimal density of schools in the area. The optimum density can be described especially from two points of view: parents and their children, and managing the community. From the point of view of parents and children, beyond the level of education, the most important is the question of the proximity of the educational building. An appropriate distance is when, if not all the vast majority of high school students can get to them by foot in 10-20 minutes. For managing the community, the most important issue is the distribution of such schools to a minimal number of schools to adequately serve students living in the community; limiting the number of schools due to the high maintenance costs of the buildings themselves and the people working in them.

Expenditure on education often reaches $30-40 \%$ of the total budget of the municipality [1]. The costs of erecting any new objects are also very high. Therefore, if we want to determine the optimal placement of schools, we need to determine the optimal numbers of schools and optimal distance to school. The optimal number of schools depends on the optimal distance to a single school. In addition, the school should have the optimum size.

If we want to learn how to optimally deploy a school, we need to find answers to specific questions.

What is the optimum distance between the school and a student's house? What is the optimal number of schools? What is the optimal size of the school? Is it possible to create a tool that will allow us to better manage the network of schools?

\section{Research}

To answer these questions, we conducted a study. We studied the scope of the territorial impact of educational buildings within the Poznan agglomeration. Analyzed in particular was the ratio of the number of educational facilities (a specific type) to the surface of individual territorial units (cities and community). The analysis was repeated, however, taking into account only the built-up area of individual cities and community.

Based on the obtained data the average radius of the impact of the type of school in a given area was analyzed. This data allowed us to verify the extent to which schools are far from the place of residence of potential students. You also could check the comfort of the road to the school and the scale of its distance. In addition, we analyzed the scale of the size of schools in various cities and community. Based on the obtained data, a pattern was compiled, contributing to determine current needs in terms of the number and size of schools.

\subsection{The assumptions}

It is assumed that the agglomeration area includes the city of Poznan and the Poznań County designated administrative boundaries [2]. Poznań County includes 
seventeen (17) community: (1) the community and the town Buk, (2) the community of Czerwonak, (3) the community of Dopiewo, (4) the community of Kleszczewo, (5) the community of Komorniki, (6) the community and the town of Kornik, (7) the community and the town of Kostrzyn, (8) the town of Lubon, (9) the community and the town of Mosina, (10) the community and the town of Murowana Goślina, (11) the community and the town of Pobiedziska, (12) the town of Puszczykowo, (13) the community of Rokietnica, (14) the community and the town of Stęszew, (15) the community of Suchy Las, (16) the community and the town of Swarzedz (17) the community of Tarnowo Podgórne. Eight of these communities are urban and rural, but the study does not distinguish between the separate areas of the city and the rest of the community. This is due to the fact that schools located in the city must also accept pupils living in the neighboring village.

Education buildings are objects or groups of buildings belonging to the entity specified by the school administration. Education buildings were divided into 3 types, based on the three-tier system of school education [3]. In connection with the distinguished educational buildings: (1) primary schools, (2) lower secondary schools, (3) secondary schools. The different types of schools were not distinguished (public, social, private, etc.), nor were schools distinguished due to the profile of education (secondary schools, technical schools, vocational schools, special, etc.).

\subsection{Analyses}

\subsubsection{The density of schools}

First analyzed was the ratio of the number of schools' given type (primary, lower secondary and secondary schools) to the surface area it takes the city or municipality, expressed in square kilometers. The results are presented in Table 1.

2.2.1.1 Primary schools In the category of primary schools, the situation is as follows: one school in the city supports the area falling within the range from $2.42 \mathrm{~km}^{2}$ to $8.20 \mathrm{~km}^{2}$, which means that the school supports in the area of a square with sides of $1.56 \mathrm{~km}$ to $2.86 \mathrm{~km}$, or an area in the shape of a circle with a radius of $0.88 \mathrm{~km}$ to $1.62 \mathrm{~km}$. For other areas the range is from $14.54 \mathrm{~km}^{2}$ to $46,53 \mathrm{~km}^{2}$, which means that the school serves an area of a square with sides of $3.81 \mathrm{~km}$ to $6.82 \mathrm{~km}$, or an area in the shape of a circle with a radius of $2.15 \mathrm{~km}$ to $3.85 \mathrm{~km}$.

2.2.1.2 Lower secondary schools In the category of lower secondary schools, the situation is as follows: one school in the city supports the area falling within the range from $3.08 \mathrm{~km}^{2}$ to $8.20 \mathrm{~km}^{2}$, which means that the school supports in an area of a square with sides of $1.76 \mathrm{~km}$ to $2.86 \mathrm{~km}$, or an area in the shape of a circle with a radius of $0.99 \mathrm{~km}$ to $1.62 \mathrm{~km}$. For other areas the range is from $20.36 \mathrm{~km}^{2}$ to $93.06 \mathrm{~km}^{2}$, which means that the school serves an area of a square with sides of $4.51 \mathrm{~km}$ to $9.65 \mathrm{~km}$, or an area in the shape of a circle with a radius of $2.55 \mathrm{~km}$ to $5.44 \mathrm{~km}$. 


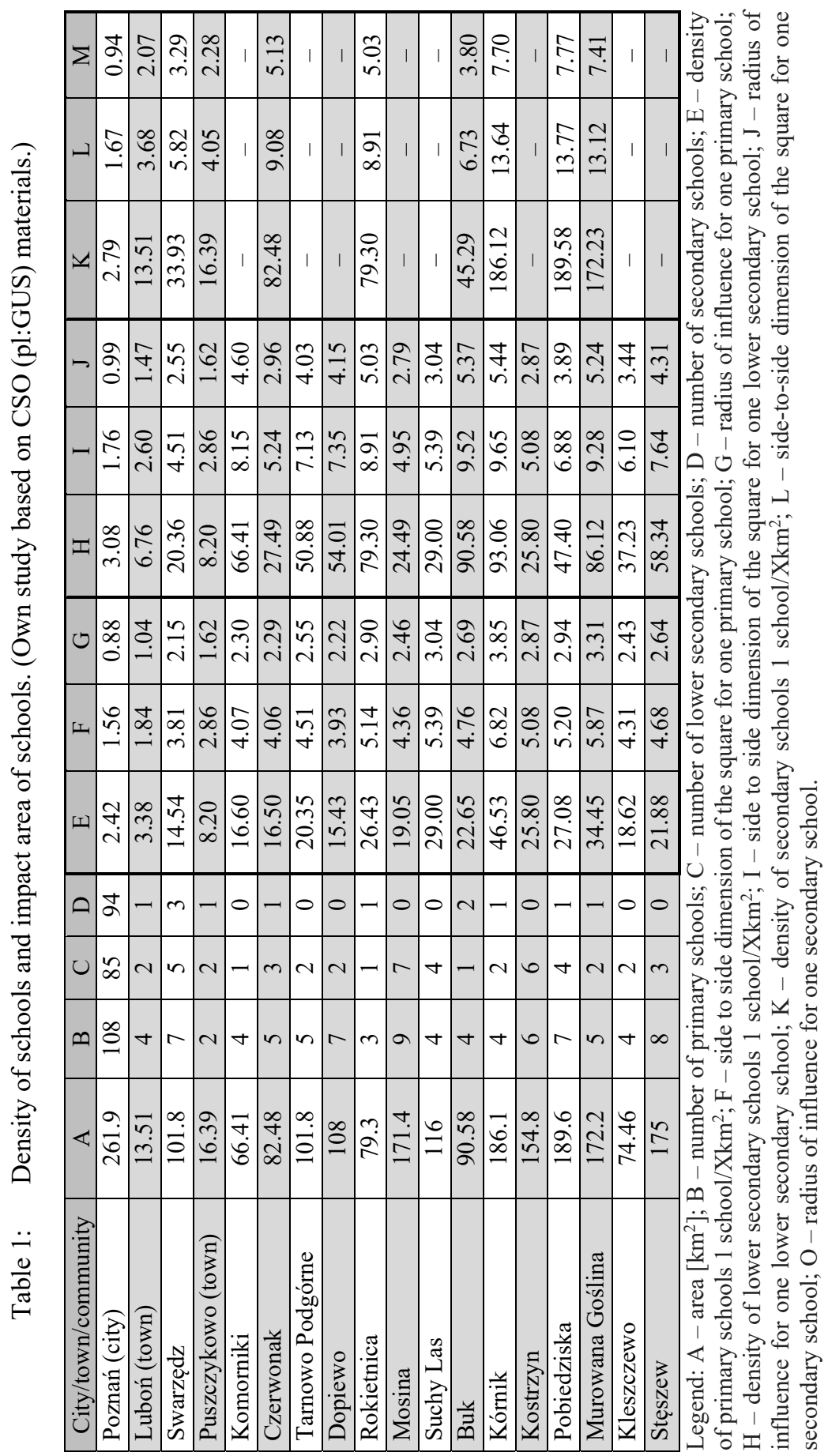


2.2.1.3 Secondary schools In the category of secondary schools, the situation is as follows: one school in the city supports the area falling within the range $2.79 \mathrm{~km}^{2}$ to $16.39 \mathrm{~km}^{2}$, which means that the school supports in the area of a square with sides of $1.67 \mathrm{~km}$ to $4.05 \mathrm{~km}$ or an area in the shape of a circle with a radius of $0.94 \mathrm{~km}$ to $2.28 \mathrm{~km}$. For other areas the range starts from $33.93 \mathrm{~km}^{2}$, which means that the school serves an area of a square with sides at least $5.82 \mathrm{~km}$, or in an area in the shape of a circle with a minimum radius of $3.29 \mathrm{~km}$.

The term upper limit requires additional study due to the fact that some communities do not have schools of this kind in their area, and young people from this area must commute to schools in neighboring communities. The distance therefore in some high schools may reach values exceeding several kilometers (see Table 1).

\subsubsection{The density of schools 2}

The above analysis does not take into account, however, the uneven distribution of population in the area of individual cities and municipalities. Urban areas as rural areas are often covered by largely undeveloped farmlands and forests. Taking into account the surface tweaks image density schools. Therefore, we made a similar analysis of the ratio of the number of schools' given type (number of primary schools, lower secondary schools and secondary schools) to the surface area it takes the city or municipality, but without taking into account the areas of crops and forests, expressed in square kilometers. The results are presented in Table 2.

2.2.2.1 Primary schools In the category of primary schools, the situation is as follows: one school in the city supports the area falling within the range $1.31 \mathrm{~km}^{2}$ to $3.13 \mathrm{~km}^{2}$, which means that the school supports an area of a square with sides of $1.14 \mathrm{~km}$ to $1.77 \mathrm{~km}$, or an area in the shape of a circle with a radius of $0.65 \mathrm{~km}$ to $1.00 \mathrm{~km}$. For other areas the range is from $2.33 \mathrm{~km}^{2}$ to $12.5 \mathrm{~km}^{2}$, which means that the school serves an area of a square with sides of $1.52 \mathrm{~km}$ to $3.54 \mathrm{~km}$, or an area in the shape of a circle with a radius of $0.86 \mathrm{~km}$ to $2.00 \mathrm{~km}$.

2.2.2.2 Lower secondary schools In the category of secondary schools, the situation is as follows: one school in the city supports the area falling within the range $1.66 \mathrm{~km}^{2}$ to $3.17 \mathrm{~km}^{2}$, which means that the school supports an area of a square with sides of $1.29 \mathrm{~km}$ to $1.78 \mathrm{~km}$, or an area in the shape of a circle with a radius of $0.73 \mathrm{~km}$ to $1.01 \mathrm{~km}$. For other areas the range is $2.98 \mathrm{~km}^{2}$ to $12.47 \mathrm{~km}^{2}$, which means that the school serves an area of a square with sides of $1.73 \mathrm{~km}$ to $3.53 \mathrm{~km}$, or an area in the shape of a circle with a radius of $0.97 \mathrm{~km}$ to $1.99 \mathrm{~km}$.

2.2.2.3 Secondary schools In the category of secondary schools, the situation is as follows: one school in the city supports the area falling within the range $1.50 \mathrm{~km}^{2}$ to $6.35 \mathrm{~km}^{2}$, which means that the school supports an area of a square with sides of $1.23 \mathrm{~km}$ to $2.52 \mathrm{~km}$, or an area in the shape of a circle with a radius of $0.69 \mathrm{~km}$ to $1.42 \mathrm{~km}$. For other areas the range starts from $4.08 \mathrm{~km}^{2}$, which means that the school serves an area of a square with sides at least $2.02 \mathrm{~km}$, or in an area in the shape of a circle with a minimum radius of $1.14 \mathrm{~km}$. The term upper limit 


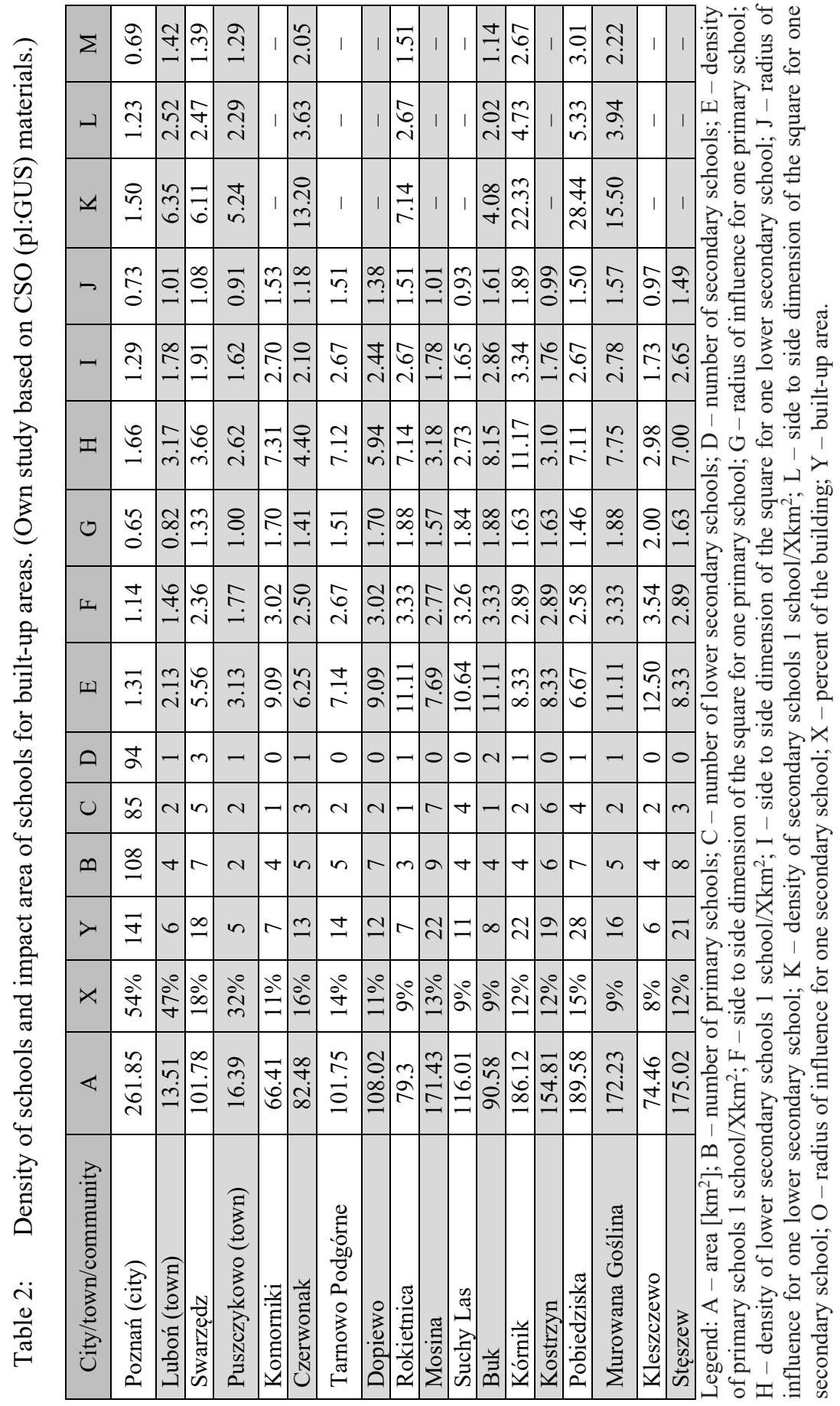


requires additional study, due to the fact that some communities do not have in their area schools of this kind, and young people from this area must commute to schools in a neighboring community. The distance therefore in some high schools may reach values exceeding several kilometers.

The results are not as clear-cut as those of the first analysis. It turns out that some rural communities have a density of schools within the range of what occurs in cities. The theoretical impact areas clearly decreased.

The impact area of elementary and lower secondary schools in cities is slightly better than the impact area of schools in other communities. Analyses indicate that secondary schools should be a separate investigation. The third level of education should be subject to a separate examination, taking into account the diversity of schools at this stage of education and the eligibility of the type of school.

\subsubsection{The distance from the school and the area development}

Until further research has been undertaken there is only study of the schools of first and second degree. After receiving information about the scope of the territorial impact of primary and lower secondary schools in various cities and communities that make up the agglomeration of Poznan, an analysis of the distance to the school is made, of three distances: (1) $500 \mathrm{~m}$, (2) $750 \mathrm{~m}$ and (3) $1000 \mathrm{~m}$.

According to many studies, an acceptable walking distance for most people in ordinary everyday situations turns out to be about 400-500 meters [4]. For children, the elderly and disabled an acceptable walking distance is often much less. According to Alexander [5], a ten-minute walk is about 500 meters (50 meters per minute) [5]. Therefore, it is assumed that the optimal distance from the primary school will be a distance of $500 \mathrm{~m}$. A distance of $1000 \mathrm{~m}$ was considered the maximum acceptable distance for walking routes to school for children studying in such institutions.

For lower secondary schools, the distance of $500 \mathrm{~m}$ was also deemed to be the most optimal distance. The maximum acceptable for a walking route to school for children studying in these institutions was 1,500 meters (about a half-hour walk). The values above were considered uncomfortable, in many situations requiring the use of a circular communication.

These assumptions included in the analysis, the percentage share of building land located in individual compartments just for different types of schools, are presented in Tables 3 and 4.

2.2.3.1 Primary schools In the category of primary schools, the situation is as follows: in cities from $29.93 \%$ to $59.99 \%$ the built-up area of the city is located 500 meters from the school. $100 \%$ of the area is located less than $1000 \mathrm{~m}$. The differences are significant for individual cities and towns. In areas for other communities from $14.6 \%$ to $52.71 \%$ the built-up area is located at a distance of $500 \mathrm{~m}$ from the primary school. $31.63 \%$ to $100 \%$ of developed communities are located less than $750 \mathrm{~m} .56 .24 \%$ to $100 \%$ of developed communities are located less than $1000 \mathrm{~m} .63 .26 \%$ to $100 \%$ of developed communities are at a distance of less than $1500 \mathrm{~m}$. In areas of suburban communities we see large disparities 
density schools. For schools in the two communities, students have to cover a distance greater than $1500 \mathrm{~m}$.

Table 3: The distance from the school and the area development for primary schools. (Own study based on CSO (pl:GUS) materials.)

\begin{tabular}{|c|c|c|c|c|c|c|c|c|}
\hline $\begin{array}{c}\text { City/town } \\
\text { /community }\end{array}$ & $\mathrm{N}$ & $\mathrm{O}$ & $\mathrm{P}$ & $\mathrm{Q}$ & $\mathrm{R}$ & $\mathrm{S}$ & $\mathrm{T}$ & $\mathrm{U}$ \\
\hline Poznań (city) & 84.78 & 190.7 & 339.1 & 763.02 & $59.96 \%$ & $134.89 \%$ & $239.83 \%$ & $539.62 \%$ \\
\hline Luboń (town) & 3.14 & 7.064 & 12.56 & 28.26 & $49.45 \%$ & $111.25 \%$ & $197.80 \%$ & $445.06 \%$ \\
\hline Swarzędz & 5.495 & 12.36 & 21.98 & 49.455 & $29.99 \%$ & $67.48 \%$ & $119.98 \%$ & $269.94 \%$ \\
\hline $\begin{array}{c}\text { Puszczykowo } \\
\text { (town) }\end{array}$ & 1.57 & 3.532 & 6.28 & 14.13 & $29.93 \%$ & $67.34 \%$ & $119.74 \%$ & $269.41 \%$ \\
\hline Komorniki & 3.14 & 7.064 & 12.56 & 28.26 & $42.98 \%$ & $96.70 \%$ & $171.93 \%$ & $386.85 \%$ \\
\hline Czerwonak & 3.925 & 8.83 & 15.7 & 35.325 & $29.74 \%$ & $66.91 \%$ & $118.97 \%$ & $267.68 \%$ \\
\hline $\begin{array}{c}\text { Tarnowo } \\
\text { Podgórne }\end{array}$ & 3.925 & 8.83 & 15.7 & 35.325 & $27.55 \%$ & $61.99 \%$ & $110.21 \%$ & $247.98 \%$ \\
\hline Dopiewo & 5.495 & 12.36 & 21.98 & 49.455 & $46.25 \%$ & $104.04 \%$ & $184.98 \%$ & $416.21 \%$ \\
\hline Rokietnica & 2.355 & 5.298 & 9.42 & 21.195 & $33.00 \%$ & $74.23 \%$ & $131.99 \%$ & $296.97 \%$ \\
\hline Mosina & 7.065 & 15.89 & 28.26 & 63.585 & $31.70 \%$ & $71.32 \%$ & $126.81 \%$ & $285.31 \%$ \\
\hline Suchy Las & 3.14 & 7.064 & 12.56 & 28.26 & $28.79 \%$ & $64.78 \%$ & $115.18 \%$ & $259.15 \%$ \\
\hline Buk & 3.14 & 7.064 & 12.56 & 28.26 & $38.52 \%$ & $86.65 \%$ & $154.07 \%$ & $346.65 \%$ \\
\hline Kórnik & 3.14 & 7.064 & 12.56 & 28.26 & $14.06 \%$ & $31.63 \%$ & $56.24 \%$ & $126.53 \%$ \\
\hline Kostrzyn & 4.71 & 10.6 & 18.84 & 42.39 & $25.35 \%$ & $57.04 \%$ & $101.41 \%$ & $228.18 \%$ \\
\hline Pobiedziska & 5.495 & 12.36 & 21.98 & 49.455 & $19.32 \%$ & $43.47 \%$ & $77.29 \%$ & $173.91 \%$ \\
\hline $\begin{array}{c}\text { Murowana } \\
\text { Goślina }\end{array}$ & 3.925 & 8.83 & 15.7 & 35.325 & $25.32 \%$ & $56.97 \%$ & $101.29 \%$ & $227.89 \%$ \\
\hline Kleszczewo & 3.14 & 7.064 & 12.56 & 28.26 & $52.71 \%$ & $118.59 \%$ & $210.85 \%$ & $474.42 \%$ \\
\hline Stęszew & 6.28 & 14.13 & 25.12 & 56.52 & $29.90 \%$ & $67.27 \%$ & $119.61 \%$ & $269.11 \%$ \\
\hline
\end{tabular}

Legend: building area at a distance from school: N - 500m; O $-750 \mathrm{~m} ; \mathrm{P}-1000 \mathrm{~m}$; Q $1500 \mathrm{~m}$; the percentage area of the building in the distance from school: $\mathrm{R}-500 \mathrm{~m} ; \mathrm{S}-$ 750m; T-1000m; U - 1500m.

2.2.3.2 Lower secondary schools In the category of lower secondary schools, the situation is as follows: in cities from $24.73 \%$ to $47.19 \%$ the built-up area of the city is located 500 meters from the lower secondary school. $100 \%$ of the area is located less than $1500 \mathrm{~m}$.

In areas of other communities from $7.03 \%$ to $25.35 \%$ the built-up area is located at a distance of $500 \mathrm{~m}$ from the lower secondary school. $15.81 \%$ to $57.04 \%$ of developed communities are located less than $750 \mathrm{~m}$. $28.12 \%$ to $100 \%$ of developed communities are located less than $1000 \mathrm{~m}$. $63.27 \%$ to $100 \%$ of the area developed communities are located less than $1500 \mathrm{~m}$. In seven communities in the range is $63.27 \%$ to $99.38 \%$. As a result, the proportion of students must cover a distance greater than $1500 \mathrm{~m}$.

The level of comfort of distance to school is higher for primary than for secondary schools. The distance to primary schools is greater than $1000 \mathrm{~m}$ in only two communities. The level of comfort of the distance to lower secondary schools is only suitable in Poznań. In other towns and communities, it is insufficient and 
very heterogeneous. This indicates the need to verify the network of lower secondary schools.

Table 4: The distance from the school and the area development for lower secondary schools. (Own study based on CSO (pl:GUS) materials.)

\begin{tabular}{|c|c|c|c|c|c|c|c|c|}
\hline $\begin{array}{l}\text { City/town/ } / \\
\text { communitya }\end{array}$ & Wa & $Z a$ & $\mathrm{AAa}$ & $\mathrm{BB} a$ & $\mathrm{CCO}$ & DDa & EEa & $\mathrm{FFa}$ \\
\hline Poznań(city)a & $66.73 \alpha$ & 150.11 & 266.90 & 600.5 & $47.19 \% \mathrm{a}$ & $106.16 \%$ & $188.76 \%$ & $424.70 \%$ \\
\hline Luboń.(town)a & $1.57 \alpha$ & $3.532 \alpha$ & $6.28 \mathrm{a}$ & 14.13a2 & $24.73 \% \mathrm{a}$ & $55.62 \% \mathrm{a}$ & $98.90 \% \mathrm{a}$ & $222.53 \% \mathrm{a}$ \\
\hline Swarzędza & $3.93 \mathrm{a}$ & $8.83 a$ & $15.7 \alpha$ & $35.33 \mathrm{a}$ & $21.42 \% \mathrm{a}$ & $48.20 \% \mathrm{a}$ & $85.70 \% \mathrm{a}$ & $192.82 \%$ \\
\hline $\begin{array}{l}\text { Puszczykowo } \\
\text { (town) a }\end{array}$ & $1.57 \alpha$ & $3.532 \mathrm{a}$ & $6.28 \mathrm{a}$ & 14130 & 200 & $67.34 \%$ & $119.74 \% \mathrm{a}$ & $1 \%$ a \\
\hline Komornikid & $0.79 a$ & $1.766 \mathrm{a}$ & $3.14 \alpha$ & 7.0650 & $10.75 \% \mathrm{a}$ & $24.17 \% \mathrm{a}$ & $42.98 \% \mathrm{a}$ & $96.71 \% \mathrm{a}$ \\
\hline Czerwonaka & 2.360 & $5.298 \mathrm{a}$ & $9.42 \alpha$ & $21.2 \mathrm{a}$ & $17.85 \%$ a & $40.15 \% \mathrm{a}$ & $71.38 \% \mathrm{a}$ & $160.61 \% \mathrm{a}$ \\
\hline Tarnowo-Podgórne & $1.57 \alpha$ & $3.532 \alpha$ & $6.28 \mathrm{a}$ & 14.130 & $11.02 \% \mathrm{\alpha}$ & $24.79 \% \mathrm{a}$ & $44.09 \% \mathrm{a}$ & $99.19 \% \alpha$ \\
\hline Dopiewoa & $1.57 a$ & $3.532 \alpha$ & $6.28 \mathrm{a}$ & $14.13 \mathrm{a}$ & $13.21 \% \mathrm{a}$ & $29.73 \% \mathrm{a}$ & $52.85 \% \mathrm{a}$ & $118.92 \% \mathrm{a}$ \\
\hline -Rokietnicad & $0.79 \alpha$ & $1.766 \mathrm{a}$ & $3.14 \alpha$ & 7.06501 & $11.00 \%$ & $24.74 \% \mathrm{\alpha}$ & $44.00 \% \mathrm{a}$ & $98.99 \%$ a \\
\hline Mosinaa & $5.50 \mathrm{a}$ & 12.362 & 21.980 & $49.46 a$ & $24.66 \%$ & $55.47 \% \mathrm{a}$ & $98.63 \% \mathrm{a}$ & $221.91 \% \mathrm{a}$ \\
\hline Suchy:Lasa & 3.140 & $7.064 \alpha$ & 12.560 & $28.26 \mathrm{a}$ & $28.79 \% \mathrm{a}$ & $64.78 \%$ & $115.18 \% \mathrm{a}$ & $259.15 \%$ \\
\hline Buk:a & $0.79 a$ & $1.766 a$ & $3.14 \alpha$ & $7.065 a$ & $9.63 \% \mathrm{\alpha}$ & $21.66 \% \mathrm{a}$ & $38.52 \% \mathrm{a}$ & $86.66 \% \mathrm{a}$ \\
\hline Kórnika & $1.57 \mathrm{a}$ & $3.532 \mathrm{a}$ & $6.28 \mathrm{a}$ & $14.13 a$ & $7.03 \% \mathrm{a}$ & $15.81 \% \mathrm{a}$ & $28.12 \% \mathrm{a}$ & $63.27 \% \mathrm{a}$ \\
\hline Kostrzyna & 4.710 & 10.5960 & 18.840 & $42.39 a$ & $25.35 \% \mathrm{a}$ & $57.04 \% \mathrm{a}$ & $101.41 \% \mathrm{a}$ & $228.18 \% \mathrm{a}$ \\
\hline Pobiedziskad & 3.140 & $7.064 a$ & 12.560 & 28.260 & $11.04 \% \mathrm{a}$ & $24.84 \% \mathrm{a}$ & $44.17 \% \mathrm{a}$ & $99.38 \% \mathrm{a}$ \\
\hline Murowana Goślina & 1.570 & $3.532 \propto$ & $6.28 a$ & $14.13 \mathrm{a}$ & $10.13 \% \mathrm{a}$ & $22.79 \%$ & $40.51 \% \mathrm{a}$ & $91.16 \% \mathrm{a}$ \\
\hline Kleszczewo a & $1.57 \alpha$ & $3.532 \alpha$ & $6.28 \mathrm{a}$ & $14.13 a$ & $26.36 \%$ & $59.29 \% \mathrm{a}$ & $105.43 \% \mathrm{a}$ & $237.21 \%$ \\
\hline Stęszewa & 2.360 & $5.298 \mathrm{a}$ & $9.42 \alpha$ & 21.20 & $11.21 \% \mathrm{a}$ & $25.23 \% \mathrm{a}$ & $44.85 \% \mathrm{a}$ & $100.92 \% \mathrm{a}$ \\
\hline
\end{tabular}

Legend: building area at a distance from school: W - 500m; Z - 750m; AA - 1000m; BB $1500 \mathrm{~m}$; the percentage area of the building in the distance from school: $\mathrm{CC}-500 \mathrm{~m}$; DD 750m; EE - 1000m; FF - 1500m.

\subsubsection{Size of schools}

We analyzed the average size of learning objects based on the average number of pupils per one school. We also analyzed the average number of classes per year (assuming that the average class size is about 25 students). In the Polish system of education, a student attends six years in primary school and three years in the school gymnasium. Therefore, it was assumed for simplicity an even distribution of students at the time and it was assumed that the total number of students between 6 and 14 years distributed in $2 / 3$ to $1 / 3$ of the primary schools and lower secondary schools. It is assumed that small schools have 1-2 classes in one age group. Medium-sized schools have 3-4 classes in one age group. Large schools have more than five classes in one age group. Small schools can be considered optimal for education. The medium-sized school is considered to be acceptable, especially in times of demographic highs. A large school is considered to be 
uncomfortable and requires reorganization. Results of the analysis are presented in Table 5.

Table 5: The distance from the school and the area development for lower secondary schools. (Own study based on CSO (pl:GUS) materials.)

\begin{tabular}{|l|l|l|l|l|l|l|}
\hline \multicolumn{1}{|c|}{ City/town/community } & \multicolumn{1}{c|}{ GG } & \multicolumn{1}{c|}{ HH } & \multicolumn{1}{c|}{ II } & \multicolumn{1}{c|}{ JJ } & \multicolumn{1}{c|}{ KK } & \multicolumn{1}{c|}{ LL } \\
\hline Poznań (city) & 30062 & 15031 & 46 & 2 & 59 & 2 \\
\hline Luboń (town) & 2321 & 1160 & 97 & 4 & 193 & 8 \\
\hline Swarzędz & 3637 & 1818 & 87 & 3 & 121 & 5 \\
\hline Puszczykowo (town) & 670 & 335 & 56 & 2 & 56 & 2 \\
\hline Komorniki & 2185 & 1093 & 91 & 4 & 364 & 15 \\
\hline Czerwonak & 1956 & 978 & 65 & 3 & 109 & 4 \\
\hline Tarnowo Podgórne & 2029 & 1015 & 68 & 3 & 169 & 7 \\
\hline Dopiewo & 2130 & 1065 & 51 & 2 & 178 & 7 \\
\hline Rokietnica & 1333 & 667 & 74 & 3 & 222 & 9 \\
\hline Mosina & 2309 & 1154 & 43 & 2 & 55 & 2 \\
\hline Suchy Las & 1503 & 752 & 63 & 3 & 63 & 3 \\
\hline Buk & 923 & 461 & 38 & 2 & 154 & 6 \\
\hline Kórnik & 2104 & 1052 & 88 & 4 & 175 & 7 \\
\hline Kostrzyn & 1373 & 687 & 38 & 2 & 38 & 2 \\
\hline Pobiedziska & 1464 & 732 & 35 & 1 & 61 & 2 \\
\hline Murowana Goślina & 2309 & 1154 & 77 & 3 & 192 & 8 \\
\hline Kleszczewo & 678 & 339 & 28 & 1 & 57 & 2 \\
\hline Stęszew & 1065 & 532 & 22 & 1 & 59 & 2 \\
\hline
\end{tabular}

Legend: GG - the number of children attending primary school; $\mathrm{HH}$ - the number of children attending lower secondary school; II - the average number of primary school pupils per one year; JJ - the average number of classes per primary school per year; KK the average number of lower secondary school pupils per one year; LL - the average number of classes per lower secondary school per year.

2.2.4.1 Primary schools Half the primary schools in the analyzed area are small schools. The other half are medium-sized. In the analyzed area there was no large school. There are small schools in two of the three cities, as in seven communities. In one city and eight communities there are medium-sized primary schools.

2.2.4.2 Lower secondary schools In the case of secondary schools in the analyzed area they are small, medium, large and even very large. In two of the three cities there is a small lower secondary school, as well as in five communities. The two communities have medium-sized lower secondary schools. The two communities have also large lower secondary schools. In one town, and in the other six communities there is a very large lower secondary school, of over 6 classes for the year.

\subsection{The formula for determining the number and size of the school}

Comparing the results of the analysis of the optimal distance (the distance of $500 \mathrm{~m}$ on $750 \mathrm{~m}$ ) and the size of school buildings (small and medium) it can be 
seen that a number of towns and communities achieved a balance between the extent of the impact and the size of the schools so that both parameters are optimal. Based on data from areas with optimum conditions, a formula can be developed to determine the optimal number of schools and their optimal size for the numbers who in the coming years take education in a particular type of school. The formula can help predict the changes that must be made years in advance. This is possible because children start school at the age of 5-6 years. Therefore, by analyzing the data on the number of lower yearbook communities and cities several years in advance the possibility of outlets, which are under their management can be estimated and react accordingly.

The formula should help in determining the number of schools serving the area. To do this, the ratio of built-up area of a community to surface that the school can handle is examined. Denominator - the area which can comfortably handle a school should be in the range of $0.7 \mathrm{~km}^{2}$ to $1.7 \mathrm{~km}^{2}$. This interval allows students living there to reach school on foot (a walk of 10-15 minutes). The formula looks like this:

$$
\frac{a}{\pi r^{2}}=b \quad r \in<0,5 \mathrm{~km}, 0,75 \mathrm{~km}>
$$

where $a$ - built-up area of a community [expressed in $\mathrm{km}^{2}$ ]; $b$ - number of schools; $r$-radius distance from school (walking distance) [expressed in $\mathrm{km}$ ].

The radius will be larger, the smaller will be the number of schools.

You can also develop a formula to help determine the size of the schools by specifying the classes in your group of age. This formula will be as follows:

$$
\frac{c}{a \cdot n}=d \quad n \in<20,30>
$$

where $a$ - built-up area of a community [expressed in $\mathrm{km}^{2}$ ]; $c$ - number of children in a given group of age; $d$-number of classes; $n$-number of students in one class. Size of class determines the size of the school. The less children in the class, the more classes you need to create which thus increases the size of the school.

Both models can be combined into one, which allows us to verify data based on the current resource, e.g. number of classes

$$
\frac{c}{\pi r^{2} \cdot n \cdot b}=d
$$

where $a$ - built-up area of a community [expressed in $\mathrm{km}^{2}$ ]; $b$ - number of schools; $c$-number of children in a given group of age; $d$ - number of classes; $r$ - radius distance from school (walking distance) [expressed in $\mathrm{km}$ ].

The radius will be larger, the smaller will be the number of schools. $n$-number of students in one class. Size of class determines the size of the school. The less children in the class, the more classes you need to create and thus increases the size of the school.

These patterns can be modified accordingly, taking into account the different organizational system of education in a given degree. This may be relevant in a situation where it is planned to reform the education system, e.g. from the six years of primary school with eight on how it is founded in Poland.

Using the formulas communities and towns will be able to adequately verify the status of the network of schools and their capabilities. The formula also allows 
us to take into account the analysis of additional schools that could be included in the transformation of lower secondary schools. This kind of change in educational reform assumes liquidation of the lower secondary schools and converts them into primary schools, for the area in question in Table 6.

Table 6: The density of primary schools after the elimination of lower secondary schools. (Own study based on CSO (pl:GUS) materials).

\begin{tabular}{|l|r|r|r|r|r|}
\hline \multicolumn{1}{|c|}{ City/town/community } & MM & \multicolumn{1}{c|}{ NN } & \multicolumn{1}{c|}{ OO } & \multicolumn{1}{c|}{ PP } & \multicolumn{1}{c|}{ QQ } \\
\hline Poznań (city) & 193 & $59.96 \%$ & $134.89 \%$ & $239.83 \%$ & $539.62 \%$ \\
\hline Luboń (town) & 6 & $49.45 \%$ & $111.25 \%$ & $197.80 \%$ & $445.06 \%$ \\
\hline Swarzędz & 12 & $29.99 \%$ & $67.48 \%$ & $119.98 \%$ & $269.94 \%$ \\
\hline Puszczykowo (town) & 4 & $29.93 \%$ & $67.34 \%$ & $119.74 \%$ & $269.41 \%$ \\
\hline Komorniki & 5 & $42.98 \%$ & $96.70 \%$ & $171.93 \%$ & $386.85 \%$ \\
\hline Czerwonak & 8 & $29.74 \%$ & $66.91 \%$ & $118.97 \%$ & $267.68 \%$ \\
\hline Tarnowo Podgórne & 7 & $27.55 \%$ & $61.99 \%$ & $110.21 \%$ & $247.98 \%$ \\
\hline Dopiewo & 9 & $46.25 \%$ & $104.04 \%$ & $184.98 \%$ & $416.21 \%$ \\
\hline Rokietnica & 4 & $33.00 \%$ & $74.23 \%$ & $131.99 \%$ & $296.97 \%$ \\
\hline Mosina & 16 & $31.70 \%$ & $71.32 \%$ & $126.81 \%$ & $285.31 \%$ \\
\hline Suchy Las & 8 & $28.79 \%$ & $64.78 \%$ & $115.18 \%$ & $259.15 \%$ \\
\hline Buk & 5 & $38.52 \%$ & $86.65 \%$ & $154.07 \%$ & $346.65 \%$ \\
\hline Kórnik & 6 & $14.06 \%$ & $31.63 \%$ & $56.24 \%$ & $126.53 \%$ \\
\hline Kostrzyn & 12 & $25.35 \%$ & $57.04 \%$ & $101.41 \%$ & $228.18 \%$ \\
\hline Pobiedziska & 11 & $19.32 \%$ & $43.47 \%$ & $77.29 \%$ & $173.91 \%$ \\
\hline Murowana Goślina & 7 & $25.32 \%$ & $56.97 \%$ & $101.29 \%$ & $227.89 \%$ \\
\hline Kleszczewo & 6 & $52.71 \%$ & $118.59 \%$ & $210.85 \%$ & $474.42 \%$ \\
\hline Stęszew & 11 & $29.90 \%$ & $67.27 \%$ & $119.61 \%$ & $269.11 \%$ \\
\hline
\end{tabular}

Legend: MM - new number of primary schools; the percentage area of the building in the distance from new number of primary school: NN-500m; OO $-750 \mathrm{~m} ; \mathrm{PP}-1000 \mathrm{~m}$; QQ - 1500m.

The above analysis shows that the elimination of lower secondary schools and their conversion would occur in primary schools to improve the comfort of the way to school students' data centers.

In the case of Poznań, the largest city agglomeration of all schools theoretically be situated at a distance less than 500 meters from the residence of students. In the other two cities schools theoretically be situated at a distance of less than 750 meters from the residence of students. In other communities, the situation would have been significantly improved. In nine communities, schools theoretically are situated at a distance of less than 750 meters from the residence of students. Only in one community the students would have to overcome the distance between 1 and $1.5 \mathrm{~km}$.

\section{Conclusions}

The proposed formulas should be converted to the corresponding program that allows you to easily manipulate variables. Then the tool would be even more useful. 
It seems necessary to make additional analyses. One of them is the analysis showing the actual grid arrangement schools in the analyzed area. The second analysis, developed on the basis of the first, should indicate the actual distance that separated school in the area of residential zones. Information obtained from these analyzes would determine the margin of error for the derived formulas.

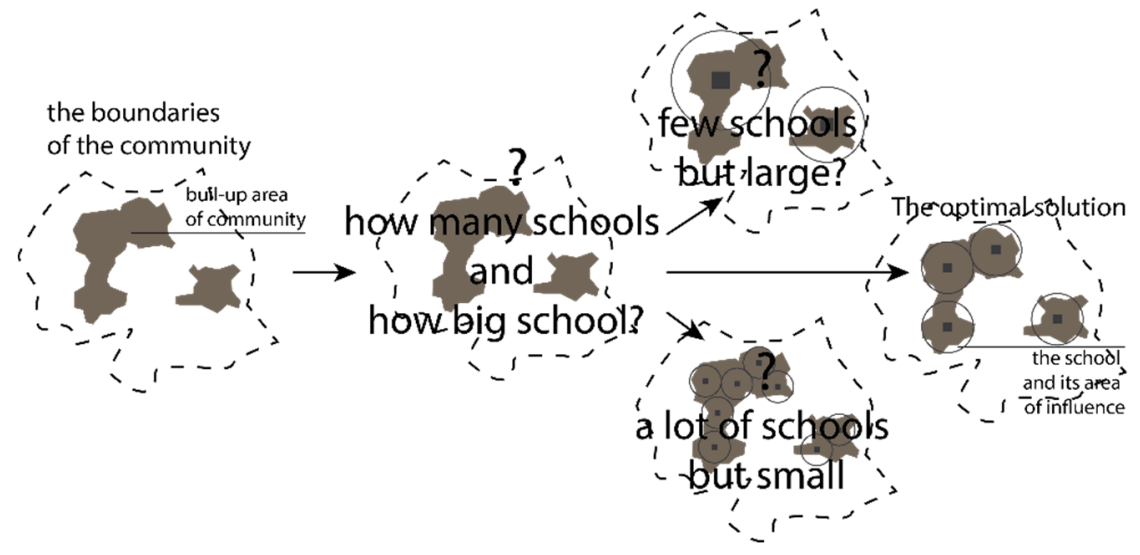

Figure 1: Decision tree.

\section{References}

[1] Central Statistical Office (http://stat.gov.pl/)

[2] Swianiewicz, P. \& Klimska, U., Social and political diversity of agglomeration in Poland - vanilla center, mosaic suburbs, Works and Geographical Studies 35, pp. 51, 53-56, 2005.

[3] Act of 7 September 1991 on the Education System (consolidated text, Journal of Laws of 2004. No. 256, item 2572 as amended).

[4] Gehl, J., Life Between Buildings: Using Public Space., RAM, Kraków, 2009, p. 137.

[5] Alexander, C., A pattern Language., GWP, Gdańsk, 2008, p. 175. 